\section{Variables influencing the mode of processing of complex stimuli*}

\author{
DONNA P. GRILL \\ The Johns Hopkins University, Baltimore, Maryland 21218
}

The present study attempts to specify some of the conditions under which parallel and serial processing may occur. The three variables studied were (1) type of task, (2) relative set for speed vs accuracy, and (3) practice. Pairs of multidimensional, geometric stimuli were presented either simultaneously or successively to $\mathrm{S}$ who was required to indicate whether they were the same or different. Each $\mathrm{S}$ participated in nine sessions. For half of the Ss speed was emphasized, and for the other half accuracy was emphasized. The results indicated that: (1) responses were faster with successive presentation than with simultaneous presentation; (2) with successive presentation, processing was serial; (3) in the simultaneous presentation condition, a gradual shift from serial to parallel processing occurred with practice; and (4) the speed and accuracy instructions used in this experiment produced no differential effects on latency or errors.

Within the past few years, attention has been directed toward the mode of processing of information provided by complex stimuli. One of the questions of chief concern has been whether information about several dimensions is processed simultaneously (in parallel) or one dimension at a time (serially). In other words, an implicit assumption on which this research has been based is that human organisms are either serial processors or parallel processors. However, the present study is founded on the assumption that humans may be capable of performing in either of these modes (and, perhaps, others as well) and that the most profitable line of study is one which attempts to specify the conditions under which parallel and serial processing can occur.

\section{Previous Research}

From the research aimed at resolving the issue of serial vs parallel processing of multidimensional information, there have emerged several studies which provide evidence in support of serial processing (Briggs \& Blaha, 1969; Burrows \& Murdock, 1969; Egeth, 1966; Harris \& Haber, 1963; Kaplan, Carvellas, \& Metlay, 1966; Nickerson, 1966; Olshavsky \& Gregg, 1970; Sternberg, 1966). On the other hand, several of the studies concerned with the issue have

*This report is based on a dissertation submitted to the graduate school, The Johns Hopkins University, in partial fulfillment of the requirements for the PhD degree, while the author held a National Defense Education Act graduate fellowship. The author gratefully acknowledges the guidance provided by Howard E. Egeth, her dissertation adviser, and by Julian $C$. Stanley and the assistance of William Hamilton, William $T$. Green, and Nelson Bingham. This research was also supported in part by a grant from the Office of Education to Dr. Howard E. Egeth. produced results which support parallel processing of multidimensional information (Donderi \& Zelnicker, 1969; Egeth \& Pachella, 1969; Hawkins, 1969; Neisser, 1963; Neisser, Novick, \& Lazar, 1963; Shurtleff \& Marsetta, 1968; Tulving \& Lindsay, 1967). And finally, the remaining studies in this body of research yield results which do not unequivocally support any one mode of processing (Atkinson, Holmgren, \& Juola, 1969; Bamber, 1969; Egeth \& Smith, 1965; Lindsay \& Lindsay, 1966; Nickerson, 1967; Sekuler \& Abrams, 1968).

On the basis of the results of previous research, it seems fairly obvious that expecting to resolve the categorical issue of serial vs parallel processing is at least unrealistic if not unwarranted. Instead, it would appear that the most profitable direction for research would be to ascertain the factors that are potential sources of variation among the results of previous studies and then to vary these factors systematically in order to determine how they affect the mode of processing. After the critical variables have been studied, we should be able to specify the combinations of these variables which will result in the various modes of processing.

\section{Relevant Variables}

A variety of multidimensional stimuli have been employed in previous research. In some studies alphanumeric characters comprised the stimulus sets (e.g., Neisser et al, 1963; Nickerson, 1966; Sternberg, 1966), while others used randomly generated figures (Briggs \& Blaha, 1969; Sekuler \& Abrams, 1968). The remaining stimuli can be separated into two types: stimuli formed from combinations of purely arbitrary dimensions which can be added or taken away at will, such as color or inscribed figure (Egeth, 1966; Harris \& Haber, 1963; Hawkins, 1969; Lindsay \& Lindsay, 1966; Nickerson, 1967), and stimuli whose dimensions are integral to the whole stimulus configuration such that without one of the dimensions the stimulus ceases to exist (Egeth \& Pachella, 1969; Tulving \& Lindsay, 1967). Examples of integral dimensions would be pitch and loudness; a tone cannot exist without both of these dimensions. The results of these latter two studies, employing stimuli composed of integral dimensions, favored parallel processing. Perhaps the inability of $S$ to define the dimensions clearly and separately makes parallel processing a more efficient mode with these stimuli.

There are two additional features which vary among these stimuli. One feature is S's preexperimental familiarity with the stimuli. Letters and numbers are highly overlearned stimuli, whereas, at the other extreme, specific randomly generated stimuli have never been encountered prior to the experiment. The second feature involves the codability of the dimensions. Following a classification by Bindra, Donderi, and Nishisato (1968), readily codable dimensions are defined as those along which levels can be individually identified in an absolute way (e.g., blue, circle, A). Stimulus dimensions that require a reference stimulus for categorization are noncodable (e.g., length of a line, loudness of a tone).

A second potential source of variation involves the type of task presented to $\mathrm{S}$. Several different types of tasks have been used, and they can be distinguished on the basis of certain characteristics. Four classes of tasks can be derived from the existing experimental paradigms. First, some of the tasks require $S$ to specifically identify the values of the dimensions (Egeth \& Pachella, 1969; Harris \& Haber, 1963; Tulving \& Lindsay, 1967 ). Second, simultaneous comparisons may be required. In this situation, $S$ is asked to compare two or more simultaneously presented stimuli with respect to some prespecified criterion (Donderi \& Zelnicker, 1969; Egeth, 1966; Hawkins, 1969; Sekuler \& Abrams, 1968). Third, a stimulus or stimuli may be defined prior to a session and $S$ then responds as to whether or not the stimulus on each trial corresponds to the memorized stimulus (e.g., Neisser et al, 1963; Nickerson, 1967; Sternberg, 1966). The fourth class of tasks involves successive comparisons between stimuli, or a modification of the third class. Typically, on each trial $E$ presents two stimuli, one after the other, with a designated interval 
between them and then asks $S$ to indicate whether or not the second stimulus corresponds to the first (Atkinson et al, 1969; Bamber, 1969; Burrows \& Murdock, 1969; Nickerson, 1966; Sternberg, 1966). The difference between the third and fourth classes of tasks is that in the former the initial stimulus remains the same over a series of trials, while in the latter the initial stimulus varies from trial to trial. These tasks can be further distinguished on the basis of the focus of the processing. Processing focuses either on the image in memory or on the physical stimulus.

The amount of practice which $S$ achieves is a third potential source of variation in results. It may be the case that different modes of processing occur at different stages of practice. In several of the studies $S s$ received extensive practice (12 days or more) on the task (Briggs \& Blaha, 1969; Egeth \& Smith, 1965; Neisser, 1963; Neisser et al, 1963; Sekuler \& Abrams, 1968).

The last potential source of variation to be discussed is the relative emphasis on speed and accuracy. Of course, this variable is relevant only to situations in which a measure of the speed of response is obtained. Fitts (1966) has shown that in RT tasks, Ss are capable of trading speed for accuracy. Since this tradeoff can affect reaction time, it would seem that control of this variable would aid in the interpretation of the effects of other variables. In the investigations heretofore considered, the treatment of this variable is not consistent. In some cases, speed is emphasized in the instructions to $\mathrm{S}$ (Neisser, 1963; Neisser et al, 1963), while in others the accuracy of the response is emphasized (Sternberg, 1966). The majority of the studies involving timed responses attempted to achieve some sort of balance between speed and accuracy by means of payoff schemes.

There exists one study in which an attempt was made to determine the influence of the speed-accuracy tradeoff on the mode of processing (Wattenbarger, 1968). The purpose of this study was to shed some light on the reasons underlying the contradictory results of Sternberg (1966) and Neisser and his associates (Neisser, 1963; Neisser et al, 1963). Wattenbarger's experiment was essentially a replication of the Neisser et al procedure, with the addition of a group of Ss instructed to perform as accurately as possible. The results indicated that $\mathrm{Ss}$ in the speed group were processing the information in parallel, a result consistent with the Neisser et al findings. However, Ss who were instructed to pay attention to accuracy were unable to scan as rapidly for multiple targets as for a single target. These results lead to the conclusion that the relative emphasis on speed vs accuracy is an important factor for serial and parallel processing, and that an emphasis on speed over accuracy can produce a shift from serial to parallel processing.

The purpose of the present study is to investigate three variables that have emerged from previous research as possible sources of variation in experimental results and to determine how these variables influence the mode of processing of information provided by complex stimuli. The three variables to be studied are: (1) practice, (2) relative set for speed vs accuracy, and (3) task.

\section{Subjects}

\section{METHOD}

Twenty-two students at The Johns Hopkins University (19 males) and two students' wives with normal uncorrected or fully corrected vision served as Ss on a volunteer basis and were paid $\$ 1.50$ per hour of participation.

\section{Stimulus Materials}

Following pilot work, three binary stimulus dimensions were chosen which met the requirement that the two values of the first dimension could be more quickly discriminated from one another than could the two values of the second dimension, and these in turn were more quickly discriminated from one another than the two values of the third dimension. The three dimensions were: (1) shape (S) represented by either an equilateral triangle, 2.5 in. on a side (all measurements refer to the image on the screen) and positioned so that none of the sides was exactly vertical or horizontal, or a circle, $2.5 \mathrm{in}$. in diam; (2) orientation of lines $(0)$ represented by four parallel lines, $0.8 \mathrm{in}$ apart, which were either vertical or horizontal; and (3) figure in center (F) represented by either a + or an $X$ in the center of the field, with intersecting lines each 0.5 in. long. Each stimulus figure was contained in a $4 \times 4$ in. square. The combination of three dimensions at three levels of dimensionality yields seven stimulus sets: S, O, F, SO, SF, OF, SOF. Stimuli of more than one dimension were constructed by superimposing the appropriate dimensions. Each set contained only the physical attributes of the dimensions relevant to that set. thus avoiding the situation in which $S$ had to ignore irrelevant variation.

Stimulus figures were drawn in black ink (No. 3 Rapidograph) on white paper and then were photographed using a Pentax Spotmatic camera. The slides were hand-mounted in Perro-color $2 \times 2$ in. precision slide binders with anti-Newton-ring glass.

For the simultaneous presentation task, a slide contained a pair of configurations each enclosed in a $4 \times 4$ in. square. The inside edges of the two squares containing the configurations were separated by $2.0 \mathrm{in}$. on the screen. The stimulus pair appearing on each trial subtended a visual angle of $8 \mathrm{deg}$ on the horizontal and $3 \mathrm{deg}$ on the vertical.

In the successive presentation task, all of the stimulus sets were composed of the same stimulus pairs as in the simultaneous presentation task except that for each pair of stimuli there were two slides. One slide contained only the left half of the original pair and the other slide contained the right half.

Construction of stimulus sets. A study of Hawkins (1969) made it clear that when stimulus sets are constructed so that the probabilities of same and different responses are equal, the states of dimensions under the multidimensional conditions are correlated. For example, in a tridimensional set, $\mathrm{XYZ}, 1$ in which one-half of the pairs are identical, one-half of the pairs are different, and the seven categories of "different" pairs contain equal numbers of stimulus pairs, if stimuli are the same along both $\mathrm{X}$ and $\mathrm{Y}$, they will be the same along $Z$ with a probability of 0.875 . This situation enables $S$ to ignore, at least partially, the most difficult dimension with little or no increase in overall error rate. In the present study, an attempt was made to control for this correlation of dimensions.

Three stimulus sets were constructed for the unidimensional conditions, one for each of the three dimensions. Each set was composed of 28 stimulus pairs such that one-half of the pairs contained stimuli which were identical with respect to the relevant dimension and one-half of the pairs contained stimuli which differed. This resulted in a probability of 0.5 that any one dimension was the same or different between the two stimuli. Only 26 of the stimulus pairs were actually used in each condition, and for each different presentation sequence a set of 26 pairs was selected randomly from the 28 .

Three sets of 32 slides were constructed for the bidimensional conditions such that one-fourth of the pairs were identical along both dimensions, one-fourth differed along both dimensions, one-fourth differed along one dimension, and one-fourth differed along the other. The probability of any single dimension's being the same was 0.5 , as was the 
probability of any dimension's being the same, given that the other dimension was the same. For each different bidimensional sequence, a set of 26 pairs was selected randomly from the 32 , with the restriction that no fewer than 6 pairs be identical along both dimensions.

For the tridimensional condition, a single set of 128 pairs was constructed such that one-eighth of the pairs were identical along all three dimensions and the seven sets representing the ways in which the pairs may differ each contributed one-eighth of the total number of pairs. Results of a pilot study by Hawkins (personal communication, 1969) indicated that since a vigilance situation occurs, a situation in which there is only 1 identical pair out of every 8 produces considerable variability of response on the part of an $\mathbf{S}$ who responds only to identical pairs. Thus, it was decided that a set of 78 pairs drawn randomly from the 128 would include the restriction that at least 15 pairs contain stimuli identical with respect to all of the dimensions. The probability of any dimension's being the same between the two stimuli, given the state of any other dimension(s), was approximately 0.62 , which is a compromise between the ideal probability of 0.5 , or chance, and a probability of 0.875 , which occurs when the set is equally divided into "same" and "different" pairs and there is an equal number of pairs in each of the seven "different" categories.

\section{Apparatus}

For the simultaneous presentation task, $S$ sat in a chair facing a translucent screen enclosed in a partition which separated two rooms. Stimuli were back-projected on the screen with a Kodak Carousel 800 projector. After being initiated by $\mathrm{E}$, each series of trials was automatically controlled. The appearance of a slide triggered a Standard clock, which was stopped by the depression of a response key available to $\mathrm{S}$. A response key was also available to $\mathrm{E}$ who terminated trials on which $\mathrm{S}$ did not respond.

Due to conditions beyond the control of $\mathrm{E}$, it was necessary to change experimental rooms following the simultaneous presentation task. For the successive presentation task, $\mathbf{S}$ sat in a chair facing a Da-Lite Silver-Lite lenticular screen, and stimuli were projected on the screen from behind $S$. Great care was taken to keep the remaining conditions constant between the two experimental rooms.

\section{Procedure}

Four experimental groups resulted from the factorial combination of two dichotomous variables. The two variables were: (1) relative set for speed vs accuracy (speed group vs accuracy group), and (2) task ( simultaneous comparison vs successive comparison). Ss were assigned randomly to the four groups.

The relative set for speed vs accuracy was manipulated by means of verbal instructions to the Ss. The speed group was informed that the purpose of the experiment was to determine the maximum response speed they could attain, and thus they were encouraged to respond as quickly as possible, whereas the accuracy group was told that the purpose of the experiment was to determine their maximum error-free response speed. (These instructions were essentially the same as those used in the Wattenbarger study.) Speed and accuracy feedback were provided after each trial.

One-half of the Ss in each of the four experimental groups were instructed to respond only when the two stimuli were identical, and the remaining half responded only when the two stimuli differed. This procedure was introduced in an attempt to eliminate the effects of response bias which are likely to occur when the "same" and "different" response systems are placed in competition (Hawkins, 1969).

All of the Ss in the experiment participated for one session on each of 9 consecutive work days. On the first day, each $\mathbf{S}$ was given instructions appropriate to his experimental group, followed by 25 practice trials using the letters " $A$ " and " $B$," and then was tested on all seven stimulus sets. On Days 2-9 $S$ was reminded of his response assignment and appropriate speed-accuracy requirements and then was given 10 warm-up trials with the letters before being tested on all seven stimulus sets. Immediately prior to a series of trials in each condition, $\mathrm{S}$ was shown a slide representative of that condition, and the dimensions were pointed out and labeled by $\mathrm{E}$.

Three orders of presentation of the seven stimulus sets were constructed, and two of the six Ss from each of the four groups (one from each response assignment) received each order. Each of the presentation orders had the following characteristics: (1) the three unidimensional sets followed one another in a block, as did the three bidimensional sets; (2) the order of the uni-, bi- and tridimensional blocks was random; (3) within the uni- and bidimensional blocks, the order of particular sets was random; (4) the order of stimuli within each set was random; and (5) all random orders were changed from day to day.

In the simultaneous comparison task, each of the seven series of trials was initiated by $\mathrm{E}$ following a verbal warning signal. A trial consisted of the appearance of a pair of configurations on the screen. The slide remained in view until $\mathbf{S}$ responded, at which time speed and accuracy information were recorded and related to $S$. Latency was measured from the onset of the stimulus pair, and the intertrial interval was $3.18 \mathrm{sec}$.

For successive presentation, a trial consisted of the appearance of a stimulus configuration on the left side of the screen. After $2.3 \mathrm{sec}$ the stimulus was removed, and the screen remained blank for 4.4 sec. At the end of this interval, a second stimulus configuration appeared on the right side of the screen and remained in view until $\mathbf{S}$ responded. Latency was measured from the onset of the second stimulus configuration, and this speed and accuracy information were recorded and related to $S$. The intertrial interval was the same as in the simultaneous presentation procedure.

Between the blocks of uni-, bi-, and tridimensional judgments there were 3-min rest periods, and rest periods of $1.5 \mathrm{~min}$ were provided between sets within the uni- and bidimensional blocks and after every 26 trials during the tridimensional block. The nature of the response system produced trials on which the nonoccurrence of a response was appropriate. On these trials, E terminated the trial after approximately $1.5 \mathrm{sec}$ by depressing a response button available to him. This action automatically initiated the next trial cycle.

\section{RESULTS AND DISCUSSION}

The data anlyses which follow provide support for these results: (1) The effect of task requirements was significant and produced faster overall mean RTs for the successive comparison task than for the simultaneous comparison task; (2) there was a significant decrease in mean RTs for both tasks with practice; (3) the instructions used in this experiment did not have any differential effects on mean RTs or percent errors; (4) there were no differences between the decision processes for "same" and "different" responses as reflected in the time required by each; (5) processing was serial in the successive comparison task; and (6) a shift from serial to parallel processing occurred with practice in the simultaneous comparison task.

\section{Treatment of Data}

The dependent variable used was reaction time. Excluded from all analyses were incorrect responses and individual RTs greater than three 
Table 1

Mean RT (Mrec) and Percent Erors (in Parentheses) Under "Same" and "Different" Response Conditions (Averased Over Days)

\begin{tabular}{|c|c|c|c|c|c|c|c|}
\hline & \multicolumn{3}{|c|}{ Unidimensional Sets } & \multicolumn{3}{|c|}{ Bidimensional Sets } & \multirow{2}{*}{$\begin{array}{c}\begin{array}{c}\text { Tridimen- } \\
\text { sional Set }\end{array} \\
\text { SOF }\end{array}$} \\
\hline & $\mathbf{S}$ & $\mathbf{0}$ & $\mathbf{F}$ & so & SF & OF & \\
\hline \multicolumn{8}{|c|}{ Simultaneous Presentation } \\
\hline $\begin{array}{l}\text { "Same" } \\
\text { RT }\end{array}$ & $\begin{array}{r}383 \\
(5.0)\end{array}$ & $\begin{array}{r}402 \\
(6.0)\end{array}$ & $\begin{array}{c}668 \\
(8.7)\end{array}$ & $\begin{array}{r}512 \\
(0.9)\end{array}$ & $\begin{array}{c}748 \\
(3.4)\end{array}$ & $\begin{array}{r}702 \\
(4.9)\end{array}$ & $\begin{array}{c}753 \\
(2.8)\end{array}$ \\
\hline $\begin{array}{l}\text { "Diffe- } \\
\text { rent"" } \\
\text { RT }\end{array}$ & $\begin{array}{r}390 \\
(7.4)\end{array}$ & $\begin{array}{c}415 \\
(4.9)\end{array}$ & $\begin{array}{c}691 \\
(8.8)\end{array}$ & $\begin{array}{c}S(O): 454 \\
O(S): 483 \\
S O: 415 \\
(13.6)\end{array}$ & $\begin{array}{c}S(F): 444 \\
F(S): 818 \\
\text { SF }: 442 \\
(11.3)\end{array}$ & $\begin{array}{c}O(F): 455 \\
F(O): 771 \\
O F: 476 \\
(14.8)\end{array}$ & $\begin{array}{c}S(O F): 466 \\
O(S F): 535 \\
F(S O): 824 \\
S O(F): 427 \\
S F(O): 465 \\
O F(S): 527 \\
S O F: 428 \\
(15.3)\end{array}$ \\
\hline $\begin{array}{l}\text { "Same" } \\
\text { RT }\end{array}$ & $\begin{array}{r}336 \\
(6.9)\end{array}$ & $\begin{array}{c}333 \\
(11.2)\end{array}$ & $\begin{array}{c}396 \\
(13.0)\end{array}$ & $\begin{array}{c}457 \\
(4.7)\end{array}$ & $\begin{array}{c}498 \\
(5.4)\end{array}$ & $\begin{array}{c}469 \\
(7.9)\end{array}$ & $\begin{array}{c}605 \\
(5.0)\end{array}$ \\
\hline $\begin{array}{l}\text { "Diffe- } \\
\text { rent" } \\
\text { RT }\end{array}$ & $\begin{array}{c}320 \\
(7.2)\end{array}$ & $\begin{array}{c}355 \\
(14.4)\end{array}$ & $\begin{array}{c}413 \\
(14.7)\end{array}$ & $\begin{array}{c}S(O): 389 \\
O(S): 424 \\
S O: 369 \\
(19.4)\end{array}$ & $\begin{array}{c}S(F): 385 \\
F(S): 576 \\
S F: 383 \\
(21.8)\end{array}$ & $\begin{array}{c}O(F): 422 \\
F(O): 542 \\
O F: 403 \\
(23.2)\end{array}$ & $\begin{array}{c}S(O F): 421 \\
O(S F): 462 \\
F(S O): 612 \\
S O(F): 382 \\
S F(O): 415 \\
O F(S): 446 \\
S O F: 382 \\
(29.2)\end{array}$ \\
\hline
\end{tabular}

Note-For "different" RT conditions, dimensions enclosed in parentheses are the same between the stimuli of a pair, and dimensions outside of parentheses provide the differences between stimuli.

standard deviations above the mean of a particular S's distribution of latencies in a given condition. (These long RTs included the cases in which $S$ failed to respond on the appropriate trial within the $1.5-\mathrm{sec}$ time allowance.)

Four Ss who participated in the simultaneous comparison condition in the original experimental room were given one session in the second experimental room as a check on the equivalence of environmental conditions. Comparisons of the data from these two rooms indicated that the particular experimental room, or projection setup, had no effect on the data.

Each $S$ in the experiment participated in a total of 63 series of trials ( 9 sessions $\times 7$ conditions). Mean reaction time was computed for each series of trials for a given $S$. An analysis of variance was performed on these mean RT data, using a multifactor repeated measurements design. Task (simultaneous comparison vs successive comparison), set (speed vs accuracy), and response assignment ("same" vs "different") were the between-groups variables, and the seven conditions and nine practice sessions were the within-Ss variables. The results of this analysis indicate that the overall mean RT for the successive comparison task was significantly faster than the overall mean RT for the simultaneous task $[F(1,16)=50.62, p<.001]$. Since the interval between the two stimulus presentations in the successive task is which the two stimuli may differ. Therefore, a one-way analysis of variance was performed on pooled "same" and "different" mean RTs at the unidimensional level (12 Ss per group). This analysis revealed no difference between the decision processes for "same" and "different" responses with respect to the time required by each $[F(1,22)<1.00]$. This finding was also obtained by Hawkins (1969) and suggests that response bias was not an important factor in these data.

An analysis of error data was prompted by the finding that the main effect of speed vs accuracy set was not significant in the analysis of RT data. The total number of errors made by each $\mathrm{S}$ was determined and converted to percent error. A one-way analysis of variance was performed on these error data with set (speed vs accuracy) as the between-groups variable (12 Ss per group). It was found that the performance of the speed group was not significantly different from that of the accuracy group with respect to errors, thus confirming the results obtained with RT data. This finding indicates that the two types of instructions given to the Ss did not affect their performance differentially. Apparently the instructions were not compelling enough to break the set which the Ss brought to the experimental situation. It is not obvious why instructions of this type served to produce the desired result in Wattenbarger's study but not in the present study. On the basis of this finding, the data from groups differing only with respect to the set for speed vs accuracy were combined for further analysis.

Table 1 gives the mean RTs (averaged over days) for "same" and "different" response conditions in the simultaneous comparison and successive comparison tasks. Each mean RT under successive presentation is faster than the corresponding mean RT under simultaneous presentation. An examination of Table 1 also reveals that in every case except one (unidimensional set $S$ under "different" response) the error rate is substantially higher for successive presentation than for simultaneous presentation. Thus, even though the instructions for speed and accuracy did not produce a significant effect, it appears that there was a speed-accuracy tradeoff with respect to task. Further study is needed to ascertain what happens to the RTs in the successive presentation task when the error rates are maintained at the same level as those in the simultaneous presentation task.

Within each multidimensional "different" set in Table 1, the trials on 


\begin{tabular}{|c|c|c|c|c|c|}
\hline & $\begin{array}{l}\text { "Same" RT"*** } \\
\text { Prediction } 1\end{array}$ & Prediction 2 & "Different" & $\begin{array}{l}\text { RT* } † \\
\text { Prediction } 3\end{array}$ & Prediction 4 \\
\hline Assumptions & $\overline{\mathrm{RT}}_{\mathrm{Z}}$ vs $\overline{\mathrm{RT}}_{(\mathrm{XYZ})}$ & 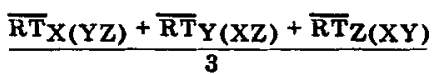 & vs $\overline{\mathrm{RT}}_{\mathrm{XYZ}}$ & $\overline{\mathrm{RT}}_{\mathrm{X}}$ vs $\overline{\mathrm{RT}}_{\mathrm{XYZ}}$ & $\overline{\mathrm{RT}}_{\mathrm{X}(\mathrm{YZ}) \text { vs } \overline{\mathrm{RT}} \mathrm{XYZ}}$ \\
\hline
\end{tabular}

Parallel/Self-Terminating

Distributed Times

$\overline{\mathbf{R T}}_{\mathrm{Z}}<\overline{\mathbf{R T}}_{(\mathrm{XYZ})}$

Constant Times

$\overline{\mathbf{R T}}_{\mathbf{Z}}=\overline{\mathbf{R T}}(\mathbf{X Y Z})$

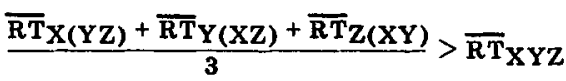

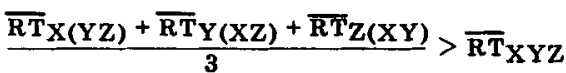

$$
\begin{aligned}
& \overline{\mathbf{R T}}_{\mathrm{X}}>\overline{\mathbf{R T}}_{\mathrm{XYZ}} \\
& \overline{\mathbf{R T}}_{\mathrm{X}}=\overline{\mathbf{R T}}_{\mathrm{XYZ}}
\end{aligned}
$$$$
\overline{\mathbf{R T}}_{X(Y Z)}>\overline{\mathbf{R T}}_{X Y Z}
$$$$
\overline{\mathbf{R T}}_{X(Y Z)}=\overline{\mathbf{R T}}_{\mathbf{X Y Z}}
$$

Parallel/Exhaustive

Distributed Times

$\overline{\mathrm{RT}}_{\mathrm{Z}}<\overline{\mathrm{RT}}_{(\mathrm{XYZ})}$

Constant Times

Serial/Self-Terminating

Random Order

$$
\overline{\mathbf{R T}}_{\mathbf{Z}}=\overline{\mathbf{R T}}_{(\mathrm{XYZ})}
$$

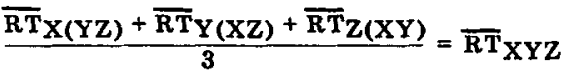

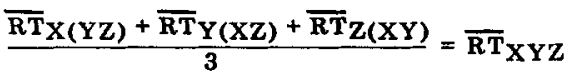

$\overline{\mathrm{RT}}_{\mathbf{X}}<\overline{\mathrm{RT}}_{\mathrm{XYZ}}$

$\overline{\mathrm{RT}} \mathrm{X}(\mathrm{YZ})=\overline{\mathrm{RT}} \mathbf{X Y Z}$

$\overline{\mathbf{R T}}_{\mathbf{X}}<\overline{\mathbf{R T}}_{\mathbf{X Y Z}}$

$$
\overline{\mathbf{R T}}_{X(Y Z)}=\overline{\mathbf{R T}}_{X Y Z}
$$

$\overline{\mathrm{RT}}_{\mathrm{X}}<\overline{\mathbf{K T}}_{\mathrm{XYZ}}$

$\overline{\mathbf{R T}}_{\mathrm{X}(\mathrm{YZ})}>\overline{\mathbf{R T}}_{\mathrm{XYZ}}$

$\overline{\mathrm{RT}}_{\mathrm{Z}}<\overline{\mathrm{RT}}_{(\mathrm{XYZ})}$

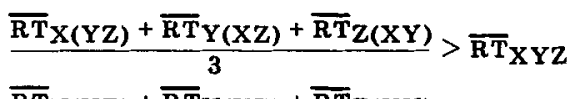

$\overline{\mathbf{R T}}_{\mathrm{Z}}<\overline{\mathbf{R T}}_{(\mathrm{XYZ})}$

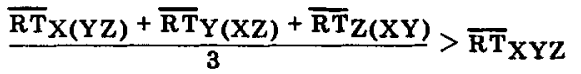

$\overline{\mathbf{R T}}_{\mathbf{X}} \leqslant \overline{\mathbf{R T}}_{\mathbf{X Y Z}}$

$\overline{\mathbf{R T}}_{\mathbf{X}(\mathrm{YZ})} \geqslant \overline{\mathbf{R T}}_{\mathbf{X Y Z}}$

Serial/Exhaustive

Random Order

$\overline{\mathrm{RT}}_{\mathrm{Z}}<\overline{\mathrm{RT}}(\mathrm{XYZ})$

Fixed Order

$\overline{\mathrm{RT}}_{\mathrm{Z}}<\overline{\mathrm{RT}}_{(\mathrm{XYZ})}$

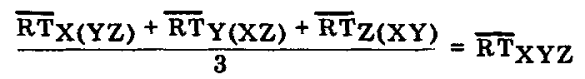

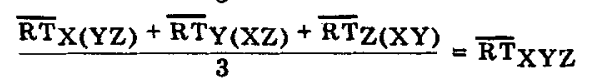$$
\overline{\mathrm{RT}}_{\mathrm{X}}<\overline{\mathrm{RT}}_{\mathrm{XYZ}}
$$$$
\overline{\mathbf{R T}} \mathbf{X}(\mathrm{YZ})=\overline{\mathbf{R T}} \mathbf{X Y Z}
$$

$\overline{\mathbf{R T}}_{\mathbf{X}}<\overline{\mathbf{R T}}_{\mathbf{X Y Z}}$
$\overline{\mathrm{RT}}_{\mathrm{X}(\mathrm{YZ})}=\overline{\mathrm{RT}}_{\mathrm{XYZ}}$

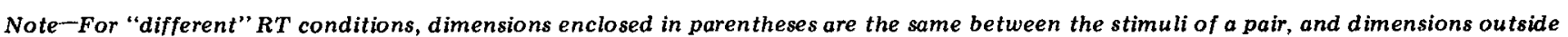
of parentheses provide the differences between stimuli.

* Where $\overline{R T}_{X}<\overline{R T}_{Y}<\overline{R T}_{Z}$.

$* * \overline{R T}(X Y Z)$ denotes $\overline{R T}$ for tridimensional stimuli identical along all dimensions.

$+\overrightarrow{R T}_{X Y Z}$ denotes $\overline{R T}$ for tridimensional stimuli differing along all dimensions.

which the dimension $F$ provided the only difference between the two stimuli produced the longest RTs for that set. For example, in the successive-presentation tridimensional "different" set, the mean RT for $\mathrm{F}$ (SO) is $612 \mathrm{msec}$, which is slower than all of the other six categories of stimulus pairs. It is obvious that this dimension was the most difficult to discriminate. The addition of at least one dimension differing between the two stimuli of a pair resulted in a decrease in mean RT. This finding suggests that on trials where two or three dimensions differed between the stimuli, the Ss may have arrived at the decision to respond "different" before completely determining the status of the $\mathrm{F}$ dimension.

\section{Evaluation of Models}

Two classes of models based on different modes of processing have been proposed by Egeth (1966) for the "same-different" RT task. The two classes of models are serial models and parallel models. Egeth selects two dichotomous attributes of serial models for consideration. The first attribute concerns the question of whether "different" judgments are made as soon as $\mathrm{S}$ detects a difference on any one dimension or whether $\mathbf{S}$ interrogates all of the relevant dimensions before making his response. The former comparison is called self-terminating and the latter, exhaustive. The second attribute considered involves the order in which dimensions are interrogated. On the one hand, S may always interrogate dimensions in the same order (fixed order), or he may vary the order of interrogation across trials (random order). Combining these dichotomous attributes results in four possible subclassifications of serial models.

Two dichotomous attributes of parallel models deserve attention. First, as with serial models, the comparison process may be either self-terminating or exhaustive. The second attribute involves the time required to make a comparison along a single dimension. This time may be either constant over all trials or it may fluctuate from trial to trial, as would be the case if comparison times were distributed like a random variable. ${ }^{2}$

There are four comparisons among stimulus conditions that are critical for deciding among the models proposed by Egeth (1966): (1) the relation between the mean "same" RT for the slowest unidimensional condition (F) and the mean "same" RT for the tridimensional condition (SOF); (2) the relation between the average of the three mean "different" RTs for the tridimensional conditions in which there is only one dimension of difference [S(OF), $O(S F)$, and $F(S O)]$ and the mean "different" RT for the tridimensional condition in which all three dimensions differ (SOF); (3) the relation between the mean "different" RT for the fastest unidimensional condition ( $S$ ) and the mean "different" RT for the tridimensional condition in which all dimensions differ (SOF); and (4) the relation between the mean "different" RT for the tridimensional condition in which there is a difference only along the most discriminable dimension [S(OF)] and the mean "different" RT for the tridimensional condition differing along all three dimensions (SOF). 3 The predictions concerning these four relations for the various models are outlined in Table 2 (adapted from Hawkins, 1969).

Since the effect of practice was significant, it is important to examine the data separately for each level of practice. A separate analysis of variance, using a single-factor repeated measurements design, was performed on mean RTs for the stimulus conditions for each Day by Task by Response set of data. In every case, the stimulus conditions differed significantly from one another $(\mathrm{p}<.001)$. The four critical comparisons were made for each of the 18 sets of RT data ( 9 days $\times 2$ tasks), and each comparison was tested against the MS from the appropriate analysis of variance (Winer, 1962, pp. 112-13). Tables 3 and 4 present 
Table 3

Mean Differences in Msec (Diff), Fs, and Directions of Significant Differences (R) for Critical Comparisons in the Simultaneous Presentation Task

\begin{tabular}{|c|c|c|c|c|c|c|c|c|c|c|c|c|}
\hline \multirow[b]{4}{*}{ Session } & \multicolumn{3}{|c|}{ "Same" RT } & \multicolumn{9}{|c|}{ "Different" RT } \\
\hline & \multirow{2}{*}{\multicolumn{3}{|c|}{$\begin{array}{l}\text { Prediction } 1 \\
\overline{\mathbf{R T}}_{\mathbf{F}} \text { vs } \overline{\mathbf{R T}}_{\text {(SOF) }}\end{array}$}} & \multicolumn{3}{|c|}{ Prediction 2} & \multirow{2}{*}{\multicolumn{3}{|c|}{$\begin{array}{l}\text { Prediction } 3 \\
\overline{\mathrm{RT}} \text { S vs } \overline{\mathrm{RT}} \text { SOF }\end{array}$}} & \multirow{2}{*}{\multicolumn{3}{|c|}{$\begin{array}{l}\text { Prediction } 4 \\
\overline{\mathrm{RT}}_{\mathrm{S}(\mathrm{OF})} \text { vs } \overline{\mathrm{RT}} \text { SOF }\end{array}$}} \\
\hline & & & & \multicolumn{3}{|c|}{$\frac{\overline{\mathbf{R T}} \mathbf{S}(\mathrm{OF})+\overline{R T}_{\mathrm{O}(\mathrm{SF})}+\mathrm{RT}_{\mathrm{F}(\mathrm{SO})}}{\text { vs } \overline{\mathrm{RT}}_{\mathrm{SOF}}}$} & & & & & & \\
\hline & Diff & $F(1,30)$ & $\mathbf{R}$ & Diff & $F(1,90)$ & $\mathbf{R}$ & Diff & $F(1,90)$ & $\mathbf{R}$ & Diff & $F(1,90)$ & $\mathbf{R}$ \\
\hline Day 1 & -175 & 14.94 & $<$ & 171 & 31.16 & $>$ & -95 & 6.41 & $\mathbf{n} \cdot \mathbf{s}$. & 52 & 1.94 & n.s. \\
\hline Day 2 & -125 & 12.56 & $<$ & 191 & 41.38 & $>$ & -55 & 2.58 & n.s. & 36 & 1.17 & n.s. \\
\hline Day 3 & -163 & 26.73 & $<$ & 194 & 46.29 & $>$ & -46 & 1.79 & n.s. & 42 & 1.41 & n.s. \\
\hline Day 4 & -86 & 10.54 & $<$ & 169 & 34.06 & $>$ & -44 & 1.57 & n.s. & 32 & 0.83 & n.s. \\
\hline Day 5 & -59 & 9.26 & $<$ & 170 & 30.03 & $>$ & -38 & 1.04 & n.s. & 18 & 0.22 & n.s. \\
\hline Day 6 & -57 & 5.76 & n.s. & 194 & 58.81 & $>$ & -21 & 0.48 & n.s. & 51 & 2.70 & n.s. \\
\hline Day 7 & -65 & 7.25 & n.s. & 189 & 73.57 & $>$ & -23 & 0.70 & n.s. & 44 & 2.72 & n.s. \\
\hline Day 8 & -28 & 1.33 & n.s. & 191 & 56.71 & $>$ & -28 & 0.81 & n.s. & 33 & 1.14 & n.s. \\
\hline Day 9 & -10 & 0.19 & n.s. & 161 & 36.66 & $>$ & $\mathbf{3}$ & 0.01 & n.s. & 25 & 0.59 & n.s. \\
\hline
\end{tabular}

the results of these comparisons.

In Tables 3 and 4, the four relations tested are presented in symbolic form at the top. For each comparison, the actual difference between the left and right sides of the relation is given with the right side subtracted from the left. The $\alpha=.01$ level of significance was adopted for all comparisons. From Table 2 it can be seen that several models predict equality between the two values of certain relations. Since absolute equality occurs very rarely in empirical data, it is necessary for comparisons between the models and the data to accept the hypothesis of no difference for those cases in which the $F$ does not reach the value required for significance at the prespecified .01 level. In Tables 3 and 4 the conclusions concerning the relations are given in symbolic form. These are the results which were compared with the predictions from the various models in Table 2.

The results of the critical comparisons among stimulus conditions in the simultaneous comparison task indicate that for Days 1-5 the data are best described by the serial/self-terminating/fixedorder model. However, the results for Days 6-9 match the predictions of the parallel/self-terminating/constanttimes model. From Table 3 it can be seen that on Days 6 and 7, even though the mean differences between $\mathrm{RT}_{\mathrm{F}}$ and $\mathrm{RT}_{\mathrm{SO}} \mathrm{F}$ for "same" data do not decrease as compared with Day 5 , the performances of the Ss become more variable. On the other hand, there is a decrease in mean difference from Days 6 and 7 to Days 8 and 9 . The mean differences in the Prediction 1 column shift gradually over practice sessions, and this shift is about as monotonic as one can hope for in psychology. This seems to indicate that there is a trend in the processing from serial to parallel, with Days 6-9 representing a period of transition.

The results for the successive presentation task, given in Table 4, present a different picture. With the exception of Day 3, the data for Days $1 \cdot 7$ best fit the serial/self-terminating/fixed-order model. On Day 3 the results support the prediction of serial self-terminating processing. However, the decision as to whether comparisons were made in a fixed or random order cannot be made on the basis of these data. One plausible explanation of this finding is that a combination of fixed and random order is employed by the Ss. For example, it could be the case that the Ss always interrogate the least discriminable dimension last but assume a random order of comparison for the other two dimensions. The only prediction that is supported by the results for Day 8 is that of exhaustive processing. The parallel/exhaustive/distributed, serial/exhaustive/fixed-order, and serial/exhaustive/random-order models all make the same predictions and, therefore, cannot be distinguished from one another in an experiment of this type. The results for Day 9 coincide with the predictions for the serial/self-terminating/fixed-order model.

Since response ("same" or "different") was a between-Ss variable, it is not possible to determine the processing mode(s) employed by individual Ss. Even though it is

Table 4

Mean Differences in Msec (Diff), Fs, and Directions of Significant Differences (R) for Critical Comparisons in the Successive Presentation Task

\begin{tabular}{|c|c|c|c|c|c|c|c|c|c|c|c|c|}
\hline \multirow[b]{4}{*}{ Session } & \multirow{2}{*}{\multicolumn{3}{|c|}{$\begin{array}{l}\text { "Same" RT } \\
\text { Prediction } 1 \\
\overline{\mathrm{RT}}_{\mathrm{F} \text { vs } \overline{\mathrm{RT}}_{\text {(SOF) }}}\end{array}$}} & \multicolumn{9}{|c|}{ "Different" RT } \\
\hline & & & & \multirow{2}{*}{\multicolumn{3}{|c|}{ 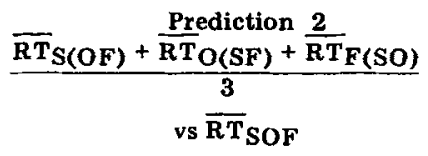 }} & \multirow{2}{*}{\multicolumn{3}{|c|}{$\begin{array}{l}\text { Prediction } 3 \\
\overline{\mathrm{RT}}_{\mathrm{S}} \text { vs } \overline{\mathrm{RT}}_{\text {SOF }}\end{array}$}} & \multirow{2}{*}{\multicolumn{3}{|c|}{$\begin{array}{c}\text { Prediction } 4 \\
\overline{R T}_{\mathrm{S}(\mathrm{OF})} \text { vs } \overline{\mathrm{RT}}_{\mathrm{SOF}}\end{array}$}} \\
\hline & & & & & & & & & & & & \\
\hline & Diff & $F(1,30)$ & $\mathbf{R}$ & Diff & $F(1,90)$ & $\mathbf{R}$ & Diff & $F(1,90)$ & $\mathbf{R}$ & Diff & $F(1,90)$ & $\mathbf{R}$ \\
\hline Day 3 & -228 & 35.32 & $<$ & 134 & 22.89 & $>$ & -99 & 8.41 & $<$ & 62 & 3.31 & n.s. \\
\hline Day 4 & -238 & 62.98 & $<$ & 114 & 20.13 & $>$ & -54 & 2.94 & n.s. & 54 & 2.98 & \\
\hline Day 5 & -212 & 42.27 & $<$ & 128 & 30.07 & $>$ & -39 & 1.86 & n.s. & 64 & 4.97 & n.s. \\
\hline Day 6 & -153 & 34.10 & $<$ & 116 & 17.13 & $>$ & -54 & 2.61 & n.s. & 55 & 2.71 & n.s. \\
\hline Day 7 & -156 & 50.16 & $<$ & 112 & 15.67 & $>$ & -27 & 0.58 & n.s. & 55 & 2.51 & n.s. \\
\hline Day 8 & -187 & 61.35 & $<$ & 66 & 6.52 & n.s. & -70 & 4.74 & n.s. & -34 & 1.12 & n.s. \\
\hline Day 9 & -177 & 41.76 & $<$ & 112 & 26.45 & $>$ & -47 & 3.03 & n.s. & 44 & 2.76 & n.s. \\
\hline
\end{tabular}


standard practice in psychology to collapse data over Ss, it would be of interest to conduct a study in which RTs to "same" and "different" responses were recorded and analyzed for individual Ss. It is possible that such an analysis would reveal individual differences in processing under the same experimental conditions.

Several conclusions can be drawn from the findings of the present study. First, it is important to examine the results for different stages of practice, since under certain conditions a shift in the mode of processing may occur in the course of practice. When data are averaged over practice sessions, the results are misleading since, as was shown in the present study, this averaging can obscure trends in the data over time which suggest a shift in the mode of processing.

Second, the processing of multidimensional stimulus information varies with the nature of the task required of $\mathbf{S}$. Within the framework of the models proposed by Egeth, when readily codable stimuli are presented simultaneously, as in the present study, Ss initially respond as predicted by the serial processing models. However, after several days of practice, the responses of the Ss tend to fit the predictions of the parallel models. Successive presentation of readily codable stimuli results in faster mean reaction times for "same" and " different" responses, but, nevertheless, Ss process the dimensions serially. With 9 days of practice, the evidence did not point to a shift in processing mode for the successive presentation task. However, there were some differences in the results across days, which suggests the possibility that with practice beyond the level reached in this study, a shift in the mode of processing might appear.

Third, it appears evident at this point that attempting to resolve the categorical issue of serial vs parallel processing is a futile approach. Since the human organism enjoys considerable flexibility of behavior, it seems highly probably that he is capable of processing information in many different ways, and, therefore, the most profitable direction for research is to try to discover what conditions are necessary for any particular mode of processing. The present study is one step in this direction, but there are many additional factors and combinations of conditions which still require investigation.

\section{REFERENCES}

ATKINSON, R. C., HOLMGREN, J. E., \& JUOLA, J. F. Processing time as influenced by the number of elements in a visual display. Perception \& Psychophysics, 1969, 6, 321-326.

BAMBER, D. Reaction times and error rates for "same"-"different" judgments of multidimensional stimuli. Perception \& Psychophysies, 1969, 6, 169-174.

BINDRA, D., DONDERI, D. C., \& NISHISATO, S. Decision latencies of "same" and "different" judgments. Perception \& Psychophysics, 1968, 3. 121-130.

BRIGGS, G. E.. \& BLAHA, J. Memory retrieval and central comparison times in information processing. Journal of Experimental Psychology, 1969, 79 395-402.

BURROWS, D., \& MURDOCK, B. B., JR. Effects of extended practice on high-speed scanning. Journal of Experimental, Psychology, 1969, 82, 231-237.

DONDERI, D. C., \& ZELNICKER, D. Parallel processing in visual same-different decisions. Perception \& Psychophysics. $1969,5,197-200$.

EGETH, H. E. Parallel versus serial processing in multidimensional stimulus discrimination. Perception \& Psychophysics, 1966, 1, 245-252.

EGETH, H. E., \& PACHELLA, R Multidimensional stimulus identification. Perception \& Psychophysics, 1969, 5, 341-346.

EGETH, H., \& SMITH, E. Categorization time and parallel vs sequential processing of memorial information. Unpublished manuscript, University of Michigan 1965.

FITTS, P. M. Cognitive aspects of information processing: III. Set for speed versus accuracy. Journal of Experimental Psychology, 1966, 71, 849-857.

HARRIS, C. S., \& HABER, R. N. Selective attention and coding in visual perception. Journal of Experimental Psychology, 1963, 65, 328-333.

HAWKINS, H. L. Parallel processing in complex visual discrimination. Perception \& Psychophysics, $1969,5,56-64$.

KAPLAN, I. T., CARVELLAS, T., \& METLAY, W. Visual search and immediate memory. Journal of Experimental Psychology, 1966, 71 488-493.

LINDSAY, R. K., \& LINDSAY, J. M Reaction time and serial versus parallel information processing. Journal of Experimental Psychology, 1966, 71, 294-303.

NEISSER, U. Decision time without reaction-time: Experiments in visual scanning. American Journal of Psychology, 1963, 76, 376-385.

NEISSER, U. Cognitive psychology. New York: Appleton-Century-Crofts, 1967.

NEISSER, U., NOVICK, R., \& LAZAR, R. Searching for ten targets simultaneously. Perceptual \& Motor Skills, 1963, 17, 955-961.

NICKERSON, R. S. Response times with a memory-dependent decision task. Journal of Experimental Psychology, 1966, 72 , 761-769.
NICKERSON, R. S. Categorization time with categories defined by disjunctions and conjunctions of stimulus attributes. Journal of Experimental Psychology, 1967, 73, 211-219.

OLSHAVSKY, R. W., \& GREGG, L. W. Information processing rates and task complexity. Journal of Experimental Psychology, 1970, 83, 131-135.

SEKULER, R. W., \& ABRAMS, M. Visual "sameness": A choice time analysis of pattern recognition processes. Journal of Experimental Psychology, 1968, 77, $232-238$.

SHURTLEFF, D. A., \& MARSETTA, M. Y. Visual search in a letter-canceling task reexamined. Journal of Experimental Psychology, 1968, 77, 19-23.

STERNBERG, S. High-speed scanning in human memory. Science, 1966, 153 , 652-654.

TULVING, E. \& LINDSAY, P. $H$. Identification of simultaneously presented simple visual and auditory stimuli. Acta Psychologica, 1967, 27, 101-109.

WATTENBARGER, B. L. Speed and accuracy set in visual search performance. Paper read at Midwestern Psychological Association meeting, Chicago, 1968.

WINER, B. J. Statistical principles in experimental design. New York: McGraw-Hill, 1962.

\section{NOTES}

1. In the tridimensional deck (XYZ) there are eight categories of stimulus pairs: (1) identical on all three dimensions, (2) different with respect to $X$, (3) different with respect to $Y,(4)$ different with respect to $Z$, (5) different with respect to $X$ and $Y$, (6) different with respect to $X$ and $Z$, (7) different with respect to $Y$ and $Z$, (8) different on all three dimensions.

2. To judge that the stimuli of a pair are identical, all dimensions must be compared. For parallel processing, this decision takes as long as the longest component. As the size of a sample increases, the mean of the longest time in a sample of statistically distributed times increases, provided there is some overlap among the distributions. Therefore, as the number of dimensions increases, the mean time required to judge that two stimuli are the same will also increase.

3. If it becomes necessary to distinguish between the serial/self-terminating/randomorder and serial/self-terminating/fixed-order models, this can be accomplished on the basis of an additional prediction about "different" RTs. For the tridimensional condition, determine the mean "different" RT separately for each dimension when it alone is different between the two stimuli. Let the fastest of these RTs be the standard and compare this standard with the mean RT of the tridimensional condition in which all three dimensions differ ( $\mathrm{RTXYZ}_{\mathrm{X}}$ ). The serial/self-terminating/random-order model predicts that the standard RT will be slower than RTXYZ. The serial/self-terminating/ fixed-order model, on the other hand, predicts that the standard RT will be the same as RTXYZ since the standard, by definition, represents the dimension that is interrogated first.

(Accepted for publication February 15, 1971.) 